\title{
LA RECEPCIÓN DE LA MÚSICA ESPAÑOLA EN THE CRITERION A TRAVÉS DE LOS ESCRITOS DE JOHN B. TREND
}

\author{
Margarita Garbisu Buesa \\ Universidad CEU San Pablo (Madrid)
}

\begin{abstract}
Resumen:
Entre 1924 y 1929 el musicólogo e hispanista inglés John Brande Trend publicó una serie de escritos dedicados a la música española en The Criterion, la célebre revista londinense, dirigida por el poeta T. S. Eliot. El presente trabajo se centra en estos escritos: se persigue analizar su contenido y relacionarlo con la obra general de Trend y con el espíritu de The Criterion. La revista respaldó una visión universal (europeísta, occidental) de la cultura, que parte del concepto de tradición, defendido por Eliot y Trend en su creación ensayística. En vinculación con este principio, uno de los temas recurrentes en estos escritos es la música de M. de Falla y la música del siglo XVI español. Trend intentó asimismo acabar con el tópico, asimilado por los lectores ingleses, de identificar la música española con la música del sur del país.
\end{abstract}

Palabras Clave:

J. B. Trend, Manuel de Falla, The Criterion, crónica musical, década de 1920, recepción, correspondencia, tradición.

\begin{abstract}
:
Between 1924 and 1929 the English hispanist and musicologist John Brande Trend published in The Criterion, the renowned London literary review edited by the poet T. S. Eliot, a serious of writings on Spanish music. The aim of the present study is to analyse these writings, their content and their relationship with the work of Trend and the editorial line of The Criterion. This literary review endorsed a universal vision of culture, in line with the concept of tradition defended by Eliot and Trend in their essays. In keeping with this attitude, one of the recurring themes is the music of Falla and the 16th Century Spanish music. Trend also tried to dispel the cliché idea that circulated in British circles that there was no other Spanish music outside Flamenco.
\end{abstract}

Key Words:

J.B. Trend, Manuel de Falla, The Criterion, music chronicle, $20^{\text {th }}$ Century Twenties, reception, correspondence, tradition.

En 1960 el profesor e hispanista inglés Edward M. Wilson donó a la cátedra Manuel de Falla de la Universidad de Granada una colección de cartas, remitidas por el creador gaditano al musicólogo y también hispanista inglés John Brande Trend. Así lo explicó Antonio Gallego Morell en un artículo publicado en el $A B C$ del 8 de enero de ese año:

“[...] Wilson llegaba a España con todo un epistolario completo de Manuel de Falla y era la Universidad de Granada quien mejor podía y merecía custodiarlo. El nuevo profesor de Cambridge ha hecho entrega oficial, por deseo de los familiares de Mr. John B. Trend, de cuantas cartas y 
tarjetas éste conservaba, testimonio de la entrañable amistad que le había ligado durante su vida con el gran compositor español, al rector de la Universidad de Granada"'.

Ahora casi cincuenta años después, el estudioso Nigel Dennis ha decidido sacar esta correspondencia a la luz en una cuidada edición, a cargo, como no podía ser de otro modo, de la Universidad de Granada y el Archivo Manuel de Falla². La publicación de esta obra está sirviendo de gran ayuda para saber más de la figura del músico español y también de la del más desconocido John B. Trend, un gran amante de nuestro país, de sus costumbres, su vida y su arte. Trend se introdujo de lleno en la España de los 20, adonde viajó asiduamente para conocer de cerca una cultura poco y mal entendida por sus paisanos; para ello no dudó en contactar con intelectuales del momento y en estudiar en profundidad la literatura y la música españolas. Como consecuencia de esta labor, sacó a la luz varios volúmenes de ensayos así como artículos diversos, que se editaron en medios ingleses de la época; uno de esos medios fue The Criterion, la revista literaria que entre 1922 y 1939 dirigió el poeta Thomas Stearns Eliot y de la que Trend se convirtió en comentarista musical.

El objetivo del presente trabajo se centra precisamente en los escritos que Trend dedicó a la música española en esta publicación. No fueron muchos, un total de siete, que se prolongaron a lo largo de la década de los veinte. Se pretende sacarlos desde aquí a la luz — algo que se estima necesario y obligado— y darlos a conocer, mostrando los puntos clave de su contenido, para probar después la existencia de un vínculo mayor o menor con sus propios volúmenes de ensayos, además de con la línea editorial de la revista. Por ello, antes de entrar en el análisis de los artículos, es obligado dedicar dos apartados previos a estudiar primero la trayectoria y producción del hispanista, y después, la vida y el pensamiento de The Criterion, así como el particular vínculo de Trend con esta importante publicación cultural del rico periodo artístico de entreguerras.

\section{John Brande Trend, musicólogo e hispanista}

En el año 1933 John Brande Trend es nombrado catedrático de español de la Universidad de Cambridge. Dada la falta de interés por el mundo hispano en la vida universitaria inglesa, se encuentra con un departamento paupérrimo que tiene que reflotar, un gran reto que afronta con emoción, tal y como le comenta a Manuel de Falla en una carta fechada en Londres el 22 de septiembre de ese año:

"Querido amigo,

No sé bien explicar ni justificar mi silencio [...]. Pero he tenido una infinidad de cartas y muchísimas preocupaciones, entre ellas, el [sic] de salir elegido catedrático en la universidad de Cambridge. ¡Figúrese! ¡Cosa tan inesperada! Y tan agradable, teniendo tantos amigos allí. Pero

1 Gallego Morell, Antonio: "Música en la universidad", en $A B C, 8$ de enero de 1960.

2 Dennis, Nigel, ed.: Manuel de Falla - J. B. Trend. Epistolario (1919-1935). Granada, Universidad de Granada, Archivo Manuel de Falla, 2007. 
en lo que se refiere al Departamento de Español, veo muchas dificultades. El local, malo; la lluvia entra por el tejado. Material escolar, malo; sin mapas buenos ni fotografías modernas [...]"3.

Ésta es una de las últimas misivas de Trend a Falla. La correspondencia entre ellos se había iniciado catorce años atrás para prolongarse hasta la Guerra Civil española. 1919-1936 se convierten, por tanto, en las fechas en las que se enmarca la relación directa de Trend con Falla y, por añadidura, con nuestro país, ya que, como se ha adelantado, durante este periodo pasa aquí largas temporadas. El nuevo cargo y el advenimiento de la guerra provocan que sus estancias disminuyan.

En 1919 Trend viene por primera vez a tierras hispanas como corresponsal de la revista The Athenaeum y, como indica Dennis, enseguida se siente hechizado por el país ${ }^{4}$. Desde entonces sus viajes se hacen constantes y Granada se convierte en su ciudad de acogida; allí conoce a Lorca y a Falla. Él mismo recuerda este primer encuentro con el músico:

"The first time I met Don Manuel de Falla was on a blustering September on the Alhambra Hill" .

Llegan después las diferentes regiones de la península y, por supuesto, Madrid con su elenco de intelectuales y artistas —Unamuno, Vázquez Díaz, Jiménez Fraud, Guillén...- a los que tratará en los años sucesivos. A menudo se aloja en la Residencia de estudiantes y su curiosidad cultural se vuelca, como no podía ser de otro modo por su formación, en la música y la literatura ${ }^{6}$.

Paradójicamente Trend había estudiado ciencias naturales en el King's College de la Universidad de Cambridge, aunque también es cierto que sin demasiado entusiasmo. Lo que de verdad le atraía eran las humanidades, la música sobre todo, en la que enseguida se aplica a fondo. En este sentido su educación es herencia directa de los intelectuales del círculo de Cambridge. Musicalmente se convirtió en uno de los mejores discípulos del crítico y estudioso Edward Dent, a quien había conocido en 1908 cuando éste era profesor visitante en el King's; con él emprendería una larga e intensa amistad. Como asegura E. M. Wilson, "Dent taught him the techniques of musical analysis and criticism and encouraged his enthusiasm". Otro de sus maestros de Cambridge es Goldsworthy Lowes Dickinson, de quien aprende "a liberal and enlightened attitude to life and to the arts"7, como también nos recuerda Wilson.

3 Íbid., pp. 215-216.

4 Íbid., p. 9.

5 Trend, John Brande: A Picture of Modern Spain: Men \& Music. Londres, Constable \& Company, 1921, p. 237.

6 Trend dedica los dos primeros capítulos de su ensayo A Picture of Modern Spain: Men \& Music (1921) al clima cultural de la España con la que se encuentra. Se titulan "Spain after the War" y "Education in Spain"; en este último se centra en la Residencia de estudiantes. Trend trata de mostrar una España intelectualmente avanzada, muy distinta a la conocida por los ingleses en ese momento.

7 Wilson, Edward M.: “John Brande Trend”, en Bulletin of Hispanic Studies, Xxxv (1958), p. 223. 
En España sus conocimientos musicales se enriquecen gracias, como es lógico intuir, a las aportaciones de Manuel de Falla. Aprende a entender la obra del maestro y la da a conocer en Inglaterra a través de conciertos, artículos, ensayos y traducciones, al tiempo que entabla con él una sincera amistad, respetuosa al tiempo, que completa una mera relación musical. De ahí que en sus cartas español e inglés hablen tanto de cuestiones personales como profesionales o que a menudo fundan ambas facetas: por ejemplo, es habitual que Trend pida a Falla su punto de vista, como compositor y amigo, sobre sus escritos ${ }^{8}$; o, por otro lado, se convierte en costumbre que Falla acuda a Trend cada vez que viaja a Londres como concertista.

Falla es también el punto de arranque de una larga labor de investigación por parte de Trend. A partir de sus enseñanzas comienza a indagar en la historia musical de España desde sus inicios y pronto se da cuenta del vacío existente en este campo; se sumerge entonces en archivos y bibliotecas para explorar los orígenes de esta arte, lo que le lleva a admirar a creadores como Tomás Luis de Victoria o Cristóbal de Morales, así como a vincularse con su colega, el historiador musical Felipe Pedrell. Fruto de todo este trabajo de investigación nacen, como se dijo, numerosas publicaciones que recorren la antigüedad y la modernidad de la música española; de entre ellas destacan A Picture of Modern Spain: Men and Music (1921), Luis Milán and the Vihuelistas (1925), The Music of Spanish History to 1600 (1926), el artículo "Catalogue of the Music in the Biblioteca Medinaceli, Madrid", publicado en la Revue Hispanique en 1927, y los escritos directamente vinculados con Falla: las traducciones del Retablo de Maese Pedro (1924) y del gongorino Soneto a Córdoba (1930), y la que quizá sea su obra más significativa: Manuel de Falla and Spanish Music (1929). El propio Falla le agradece infinitamente este trabajo en carta del 11 de noviembre de 1929:

"Amigo muy querido:

En este instante me llega su libro, y quiero en seguida decirle la emoción y gratitud profundas con que recibo esta nueva y grande prueba de su afecto y de su amistad, que tanto me honran y a los que tan de corazón correspondo".

Como se puede apreciar, todos los textos mentados se circunscriben a la década de los 20. Ello no implica que en estos años su curiosidad por otros aspectos de nuestra cultura fuera inexistente, pues ya sabemos que en España conoce y entabla una profunda amistad con un buen número de intelectuales, especialmente literatos: desde Unamuno, hasta los miembros de la generación del 27. No en vano entre sus colaboraciones con revistas inglesas de esta época, se encuentran reseñas de la obra de autores españoles del momento.

8 Sirva como ejemplo la traducción al inglés y el estreno en el Reino Unido del Retablo del Maese Pedro, asunto que llena un buen número de misivas.

9 Dennis, Nigel, ed.: Manuel de Falla - J. B. Trend. Epistolario (1919-1935), op. cit., p. 176. 
No obstante, hay que esperar a los 30 para encontrar profundas y extensas reflexiones críticas con firma de Trend sobre las letras hispanas. No deja de tener lógica pues es obvio pensar que su actividad como crítico literario aumenta cuando accede a la cátedra de español en 1933; por ello, salvo obras como, entre otras, la versión Life's a Dream de Calderón, de 1925, Alfonso the Sage and other Essays, de 1926, o Spanish Short Stories of the Sixteenth Century, de 1928, la mayoría de sus ensayos y traducciones en torno a nuestra literatura se sitúan a partir de la segunda mitad de la década de los 30 (en plena guerra civil) para prolongarse durante los 40 y los 50. Algunos títulos son los siguientes: como editor y traductor, Prosa diversa de Unamuno (1938), Prose and Verse del Marqués de Santillana (1940) o Fifty Spanish Poems de Juan Ramón Jiménez (1950); como ensayista, "Calderón and the Spanish Religious Theatre of the Seventeenth Century" (1938), Antonio Machado (1953), o la serie de separatas publicadas por la Universidad de Cambridge dedicadas a Guillén, Lorca, Darío, Berceo y San Juan de la Cruz, que quedarán después recogidas en Lorca and the Spanish Poetic Tradition (1956).

Dos aspectos llaman la atención de la creación de Trend a partir de los 30: por un lado, la práctica ausencia de escritos sobre música en coincidencia con su preferencia por lo literario (a este respecto, destacamos un memorial dedicado a Dent en su muerte en 1958, publicado en The Score $)^{10}$, y por otro, el hecho de que el contenido de todas sus creaciones literarias se dirija o bien a poetas por él conocidos (los de la España de los 20 hasta la guerra), o bien a autores de unos cuantos siglos atrás en el tiempo. Es decir, Trend no dedica una sola palabra a las letras españolas contemporáneas, esto es, a la literatura de posguerra; ¿por qué? Porque, como asegura Dennis, Trend comprende que a partir de 1936 "su España" se ha acabado ${ }^{11}$.

Ya se ha comentado que con la cátedra y la contienda, los viajes del crítico a la Península disminuyen ante la inestable situación política española y el exceso de trabajo que acarrea su nuevo cargo; existe, sin embargo, un tercer motivo, más real si cabe que los anteriores, que justifica su alejamiento hispano: el rechazo a los nuevos tiempos. Aunque manifiestamente apolítico, su mentalidad liberal y su amor por nuestro país no le consienten soportar el levantamiento y la posterior dictadura; por ello, Trend se opone al nuevo régimen y se convierte en portavoz de la República en el Reino Unido, al tiempo que ayuda a intelectuales exiliados ${ }^{12}$; por ello, la nueva España -a pesar de su reciente trabajo- deja de

10 Trend, John Brande: "Dent", en The Score, (febrero 1958), pp. 49-55.

11 Dennis, Nigel, ed.: Manuel de Falla - J. B. Trend. Epistolario (1919-1935), op. cit., p. 22.

12 Dennis así nos lo recuerda:

"Durante la guerra civil, Trend no deja de expresar su apoyo a la República así como a los valores culturales y éticos que representa para él. La carta que envía al Times Literary Supplement en el otoño de 1936, comentando el asesinato de Lorca, expresa toda la indignación y el dolor que siente [...] Al año siguiente se encarga personalmente de acoger en Cambridge a un grupo de refugiados vascos -la mayoría de ellos niños- que han huido de los horrores de la guerra. En 1939 [...] se apresura a ofrecer asilo en la Universidad a su amigo Antonio Machado y, con la ayuda de Dent, consigue un puesto en King's College para Roberto Gerhard". (Dennis, Nigel, ed.: Manuel de Falla - J. B. Trend. Epistolario (1919-1935), op. cit., p. 22).

Por su parte el poeta Jorge Guillén, que había sido lector de español en la Universidad de Oxford entre 1929 y 1931, le comenta en carta de marzo de 1938, a su amigo Pedro Salinas:

"Y para mí no habrá más descanso dominical que el de un lectorado en el extranjero. Acabo de escribir a Trend -pero con muy poca esperanza. Cambridge sería la mejor solución”. (SAlinas, Pedro; GuILlén, Jorge: Correspondencia. 1923-1951. Barcelona, Tusquets, 1992, p. 187). 
interesarle culturalmente pues ya nada tiene que ver con la de la República, viva e intensa intelectual y artísticamente; y por ello, sus textos de crítica literaria vuelven sus ojos a la preguerra, al medioevo y a los siglos de oro.

En definitiva, Trend el musicólogo, el docente y el siempre hispanista, no cesó de escribir sobre España a lo largo de su carrera, y como tal, además de publicar los citados ensayos, colaboró, como sabemos, con diversas publicaciones periódicas inglesas dando a conocer lo español en su país. Algunos de estos artículos formaron parte después de sus volúmenes, si bien a menudo tendía a modificarlos. La intención que con ellos Trend perseguía era dar a conocer al público inglés la cultura de la Península y, sobre todo, mostrar una visión de España diferente a la estereotipada; una España alejada de los tópicos del abanico y el flamenco. En palabras de Dennis:

“[...] se asigna a sí mismo la responsabilidad de hacer de puente o intermediario entre España e Inglaterra, explicando al público británico el sentido de la cultura española, en su dimensión histórica y actual. [...] Nadie mejor que él [...] para emprender la tarea de explicar la naturaleza de esa España esencial a un público angloparlante -un público curioso, sin duda, pero mal informado, que no ve más allá de las leyendas románticas y los estereotipos culturales" 13 .

Sus colaboraciones fueron tantas que en ocasiones se le ha reprochado el repetirse, o lo que es lo mismo, se le ha acusado de volcar información idéntica en dos artículos de dos revistas diversas. A ello se refiere Wilson cuando menciona que publicó el mismo ensayo sobre La Galatea de Cervantes de cuatro formas distintas:

"It was inevitable that one who wrote so much should sometimes have repeated himself. One essay (that on Cervantes's Galatea) appeared in four different forms with four different titles"14.

Las revistas inglesas en las que publicó de forma asidua fueron, entre otras, The Athenaeum, Music and Letters, Times Literary Supplement, The Musical Times, Monthly Musical Record, el Boletín del Instituto Español y, finalmente y como ha quedado claro desde el principio, The Criterion de T. S. Eliot.

Guillén, aunque en esos momentos tiene una cátedra en la Universidad de Sevilla, está barajando el exilio; en efecto, abandona el país en julio del 38 no hacia Reino Unido sino hacia Estados Unidos, en donde encuentra un puesto en la Universidad de Vermont.

13 Dennis, Nigel, ed.: Manuel de Falla - J. B. Trend. Epistolario (1919-1935), op. cit., p. 10.

14 WILson, Edward M.: "John Brande Trend", op. cit., p. 225. 


\section{John Brande Trend y The Criterion (1922-1939)}

Cuando John B. Trend publica en 1924 su primer escrito en The Criterion, la revista ya contaba con dos años de andadura; cuando en 1933 publica el último, aún le quedan seis años de existencia. $\mathrm{Su}$ trayectoria empieza en 1922 y finaliza en 1939; muere por la guerra y el puro desgaste de la publicación, y nace por la iniciativa del gran poeta T. S Eliot.

En carta con fecha del 14 de julio de 1921, Eliot comunica a Ottoline Morrell la posibilidad de poner en marcha una publicación literaria bajo el auspicio de Mary Lilian Rothermere, la mujer del dueño del Daily Mail:

"There has been a project for the revival of Art and Letters, or rather as it now appears, a quarterly of similar size under a new name. It has undergone various transformations and passed through various hands since it was first broached to me [...] the person to provide money is Lady Rothermere" 15 .

Tras duros meses de trabajo, el proyecto se hace realidad cuando el 15 de octubre de 1922 sale a la luz The Criterion; entonces se desconocía que permanecería viva, siempre bajo el mismo director, durante casi dos décadas y cuatro etapas diferentes.

El primer momento de The Criterion abarca desde su nacimiento hasta enero de 1926, fecha en la que nace The New Criterion o la segunda época de la publicación; llega ésta hasta julio de 1927, mes en que surge The Monthly Criterion, con periodicidad mensual (hasta entonces era trimestral); es la etapa más corta de la revista, pues once meses después, en junio de 1928, empieza el cuarto y último momento de la publicación, que recupera la denominación y periodicidad inicial y se convierte, por tanto, en el The Criterion de los primeros tiempos. Muere definitivamente en enero de 1939.

Desde un principio Eliot persigue que la línea de la revista se ajuste a tres objetivos fundamentales: ser actual pero apolítica; abarcar diferentes disciplinas artísticas y no ceñirse exclusivamente a lo literario; y, fundamentalmente, respaldar una visión universal (o europeísta) de la cultura, acogiendo la voz y la pluma de autores de otras partes del mundo. Así lo declara a sus lectores en los dos editoriales que saludan la primera y la segunda época de la publicación: en el titulado "The Function of a Literary Review", en donde explica sus dos primeras intenciones:

"It is the function of a literary review to maintain the autonomy and disinterestedness of literature, and at the same time to exhibit the relations of literature-not to 'life', as something contrasted to literature, but to all the other activities, which, together with literature, are the components of life"16

15 Eliot, Valerie, ed.: The Letters of T. S. Eliot. Volumen 1: 1898-1922. London, Faber \& Faber, 1988, p. 461.

16 Eliot, T. S.: "The Function of a Literary Review, en The Criterion, I/4 (1923), p. 421. 
y en "The Idea of a Literary Review”, en donde menta el europeísmo:

"[...] we must include [...] the work of continental writers of the same order of merit as our own"17.

Este último aspecto no era algo nuevo en Eliot, pues ya en 1919 había mostrado su defensa de una cultura universal (occidental, europea) en "Tradition and the Individual Talent", uno de sus más célebres ensayos, en el que expone el concepto de tradición, que conlleva lo siguiente:

"[...] the historical sense involves a perception, not only of the pastness of the past, but of its presence; the historical sense compels a man to write not merely with his own generation in his bones, but with a feeling that the whole of the literature of Europe from Homer and within it the whole of the literature of his own country has a simultaneous existence and composes simultaneous order"18.

Esto es, Eliot entiende la tradición como el medio de convertir la literatura (siempre se refiere a esta disciplina por su condición de poeta) en atemporal o, dicho de otro modo, como la herencia de un pasado que todo creador ha de vincular con su presente literario, si bien pasado y presente no deben circunscribirse a un entorno inmediato, o sea, al país, cultura o idioma propios. En suma, no hablemos de una cultura inglesa, española, francesa o de una cultura medieval, moderna o contemporánea; hablemos de una cultura universal, o hablemos, simplemente, de cultura.

Al amparo de este espíritu se fragua The Criterion y se fraguan también otras tantas revistas culturales de las primeras décadas del xx y el periodo de entreguerras: entre otras, la Nouvelle Revue Française en Francia, la orteguiana Revista de Occidente en España o Il Convegno en Italia. Todas ellas se hermanaron colaborando entre sí y comprometiéndose a introducir la cultura de los demás países occidentales en sus páginas. De ahí que The Criterion reseñara lo publicado en el resto de las revistas europeas, que cediera espacio a la creación de Proust, Dostoievsky, Pirandello, Valéry o Hesse y que, además, se preocupara por dar a conocer la vida artística europea a través de un nutrido número de cronistas y colaboradores que traían noticias de Francia, Alemania, Italia o España. En concreto, quien dio cuenta de la cultura española enviando sus crónicas desde Madrid fue Antonio Marichalar, asiduo colaborador de la Revista de Occidente. Ahora bien, John Brande Trend, por su conocimiento directo del tema, también participó en esta labor con la publicación de muchos escritos vinculados con España: reseñas, traducciones de textos (entre los que se encontraban las propias crónicas de Marichalar), etc.

Pero si Eliot contó desde el principio con Trend para que engrosara el elenco de colaboradores de su revista, no fue por su faceta como hispanista, sino más bien por su labor como musicólogo; no olvidemos que el poeta no quiso limitar la publicación a información exclusivamente literaria sino

17 Eliot, T. S.: “The Idea of a Literary Review”, en The Criterion, iv/1 (1926), p. 4.

18 Eliot, T. S.: "Tradition and the Individual Talent", en Selected Essays. London, Faber \& Faber, 1999, p. 14. 
abrirla a todas las disciplinas del arte, y Trend para entonces tenía ya un nombre en su país como estudioso musical y había trabajado con otras muchas publicaciones; de ahí que fuera el elegido de Eliot:

"Guiado y alentado por su amigo Dent [...] va ampliando sus intereses y desarrollando sus conocimientos hasta convertirse en los años 20 en unos de los más autorizados comentaristas en Inglaterra sobre temas musicales. Prueba de ellos es la aparición de su nombre en las páginas de The Criterion, revista cultural de gran prestigio en la época, para la cual nada menos que T. S. Eliot, su director, le encarga una sección regular sobre asuntos musicales"19.

En realidad, la primera colaboración de Trend con The Criterion como musicólogo no forma parte, como afirma N. Dennis, de ninguna sección regular; se trata de un estudio sobre precisamente música española, titulado "The Moors in Spanish Music" y publicado en el número 6 de febrero de 1924. La sección regular comienza, bajo el epígrafe "Music" (más tarde "Music Chronicle"), tres entregas después, en el número 9, de octubre de 1924. En ella, ejemplar a ejemplar, Trend aporta su punto de vista sobre el panorama musical europeo, lo que le convierte en el comentarista oficial de Criterion en esta disciplina, con plena libertad para acercarse a esta arte en cualquier país y época, de acuerdo precisamente con el espíritu universal de la revista, del que Trend no se siente totalmente desvinculado.

Es más, probablemente fue éste otro de los motivos que llevó al director a contar con el musicólogo. Porque Trend -como Eliot- cree también en la tradición y en una cultura sin límites temporales que aúne pasado, presente y futuro. Expresado en términos musicales, Trend considera que el compositor contemporáneo es pleno deudor de las melodías antiguas, sean éstas populares o cultas. Así lo explica en el prólogo a Manuel de Falla and Spanish Music, al asegurar que el cambio o renacer vivido en la composición europea desde el siglo xIX fue debido a un "getting down to facts", esto es, a una recuperación de los valores de la música antigua:

"Yet the 'facts' of a country's music are not, entirely and exclusively, folk-song and folk-dance, or the melodic and rhythmic features peculiar to them. The facts include also the tradition of cultivated music..." 20 .

La tradición de la música antigua convierte el arte en intemporal, al vincularse el pasado con el presente y con su proyección en el futuro:

19 Dennis, Nigel, ed.: Manuel de Falla - J. B. Trend. Epistolario (1919-1935), op. cit., p. 14.

20 Trend, J. B.: Manuel de Falla and Spanish Music. New York, Alfred A. Knopf, 1934, p. XVI. 
"For to us, men and women of today, it is surely not extravagant to imagine that the past has existed mainly for our benefit, to spare or spoil as we may; just as we exist (if we create anything) not for ourselves or only for our own age, but also for the future"21.

Eliot en sus ensayos había explicado la tradición con ejemplos extraídos de la literatura; Trend está haciendo lo propio con la música; en definitiva, dos artes distintas que conducen a un mismo concepto.

Con el inicio de la segunda etapa, la actividad de Trend en la revista se intensifica, no ya solo por las colaboraciones que publica en cada número, sino también porque participa en las más o menos informales reuniones que Eliot mantenía semanalmente con el llamado "Grupo Criterion", formado por una serie de intelectuales -entre los que se encuentra Trend- que asesoraban al poeta en la dirección ${ }^{22}$. Los años de la segunda mitad de los veinte se convierten, por tanto, en el momento de mayor vínculo del hispanista con Criterion, lo que, sin embargo, no impide que en los treinta abandone la publicación. En concreto, su última colaboración como comentarista musical se encuentra en el número cuarenta y nueve, de julio de $1933^{23}$. En la siguiente entrega (de octubre 1933), desaparece momentáneamente la sección, y a partir del número cincuenta y uno, la "Music Chronicle" corre a cargo de Philip F. Radcliffe.

Cabe destacar, en este sentido, que el vínculo de Trend con Criterion se interrumpe no sólo en el campo musical, sino también en su eventual faceta como hispanista; deja de traducir las crónicas de Antonio Marichalar, y deja de redactar reseñas relacionadas con las letras hispanas. A partir del 33, las crónicas de Marichalar pasan a ser publicadas en versión de Charles K. Colhoun, quien se convierte en el máximo especialista de la cultura de nuestro país en la revista.

Es fácil comprender que el principal motivo de la ruptura fue la cátedra en Cambridge, en la que se inicia en el 33; sin embargo, Wilson sugiere otra posible causa, según se desprende de las siguientes palabras:

"He was also associated with The Criterion (edited by Mr. T. S. Eliot) in the twenties, but the strains of the next decade destroyed what had been a considerable cultural force, and henceforth he belonged to no group of writers" 24 .

"The strains" o las tensiones a las que Wilson se refiere no son otras que las originadas por los problemas que atraviesa la revista a partir de su cuarta época, cuando se aleja de los principios que le habían dado vida y adquiere un cariz más ideológico, que abre el camino hacia su declive. La mayoría de los estudiosos coinciden al explicar que el principio del fin de Criterion se sitúa entre 1928 y 1929 , meses después de la conversión de Eliot al catolicismo.

21 Ibíd., pp. XVI-XVII.

22 Otros de los miembros del grupo fueron Herbert Read, F. S. Flint, Harold Monro, Bonamy Dobrée, Frank Morley y Richard Church. Los encuentros semanales tenían lugar en el céntrico restaurante Commercio, en Soho, o en el Swiss Hotel; si almorzaban, las comidas se celebraban en el pub Cock en Fleet Street, y más adelante, todos lo jueves, en la taberna Grove en South Kensington.

23 J. B. Trend: "Music Chronicle. An Italian Critic", en The Criterion, xII/49 (1933), pp. 648-653.

24 WiLson, Edward M.: "John Brande Trend", op. cit., p. 223. 
No es casual esta circunstancia porque la nueva condición religiosa del poeta camina de la mano de una cada vez más asidua lectura de la obra de Charles Maurràs y una ulterior progresión hacia un conservadurismo ideológico del que no queda libre Criterion ${ }^{25}$. Consiguientemente, el apoliticismo inicial peligra, la impronta cultural y artística va siendo devorada por un creciente número de páginas de contenido ideológico, y el espíritu universal, verdadero motor de la publicación, aunque no desparece, sí estrecha su cerco de voces extranjeras. Ello provoca que el número de suscriptores descienda, al tiempo que muchos de las firmas iniciales, ajenas al nuevo pensamiento eliotiano o simplemente hastiadas ante el declinar de la revista, abandonen su colaboración. Entre ellas, el propio Trend.

No olvidemos, en este sentido, que el inglés siempre había defendido una visión liberal de la cultura; solo unos años después apoyaría la República española, con lo que culturalmente significaba, y rechazaría la España franquista en todos sus aspectos. Es, por tanto, lícito pensar que en los 30 Trend ya no comulga con un Criterion cada vez más sesgado en sus puntos de vista, lo que posiblemente le ayuda al abandono definitivo en 1933, el año en que es nombrado catedrático.

Pero hasta entonces, han pasado nueve años desde que en 1924 Trend había comenzado a escribir para Criterion; nueve años, tres etapas y un considerable número de entregas en la mayoría de las cuales dejó su impronta con sus artículos musicales. Ya sabemos que hasta 1929 varios de ellos se detienen en nuestro país, en justa coincidencia con su gran dedicación a la investigación musical española, las publicaciones resultantes y el afianzamiento de su amistad con Falla; por consiguiente, no resulta extraño que, aunque en sus numerosos escritos en la revista se introdujera en la música de cualquier rincón de Europa, a menudo recalara en su querida España. Detengámonos a continuación en estos escritos, exponiendo primero objetivamente sus ideas fundamentales para llegar después a unas últimas conclusiones.

\section{La música española en los escritos de Trend para Criterion}

Como se mencionó, se trata de un total de siete escritos cuyos títulos y referencias son los siguientes: "The Moors in Spanish Music" (The Criterion, II, 6, febrero 1924, pp. 204-219); "Music. The Spanish Idiom" (The Criterion, III/12, julio 1925, pp. 564-569); "Music. Spain and Hungary" (The New Criterion, iv/1, enero 1926, pp. 154-160); "Music. Musicians and Philosophers" (The New Criterion, Iv/2, abril 1926, pp. 342-349); "Music. A Contemporary of the Tudors" (The New Criterion, Iv/3, junio 1926, pp. 563-569); "Music Chronicle. Falla and the Ballet" (The Criterion, vIII/32, abril 1929, pp. 480-486); "Music Chronicle. The Present State of Contemporary Music" (The Criterion, IX/34, octubre 1929, pp. 96-102).

25 En concreto, Eliot se bautiza en junio de 1927 y en 1928 publica su célebre For Lancelot Andrewes, ensayo en el que proclama ser "Classicist in literature, royalist in politics and anglo-catholic in religion", en clara respuesta al espíritu de Maurras, descrito como la encarnación de tres tradiciones: "Classique, catholique, monarchique". 
A simple vista y sin adentrarnos aún en el análisis de cada uno de ellos, varios aspectos llaman la atención. El primero quedó ya adelantado cuando afirmamos que el estreno de Trend en la revista no se incluye en sección alguna, en este caso, en "Music" o "Music Chronicle", pues aún no había sido creada. El segundo aspecto se ajusta a criterios cronológicos; desde esta perspectiva se observa, por un lado, que el año 1926 es el más rico en presencia hispana y, por otro, que los dos primeros escritos se sitúan en la primera época de la revista, los tres siguientes en la segunda y los dos últimos en la cuarta, sin encontrarse rastro de música española en el Monthly Criterion (lo que tampoco sorprende demasiado ya que fue la etapa más corta de la vida de la publicación). El tercer aspecto se refiere los títulos que encabezan los artículos, sólo en cuatro de los cuales aparece explícita la presencia de nuestro país; respecto a los tres restantes, hay que adentrarse en la lectura del contenido para ver el protagonismo español. Digamos además que, si aplicamos la misma lógica para Falla, es fácil comprobar que mención clara al compositor únicamente se encuentra en el epígrafe "Music Chronicle. Falla and the Ballet".

A todo ello hay que añadir que no se puede dejar de entender estas colaboraciones sin perder de vista que la intención inicial de Trend -que ya sugerimos en páginas anteriores- es la misma que la que persiguió en todas sus colaboraciones para publicaciones periódicas de su país: dar a conocer a un ignorante público inglés la cultura española. Finalmente, un apunte formal completa esta reflexión inicial: aunque sus escritos parten siempre de un dato concreto -el germen del comentario-, en todos ellos, el "periodista" acaba desapareciendo para aparecer el musicólogo; es decir, en todos ellos la anécdota inicial queda diluida en un más sesudo discurso, en el que un Trend orgulloso expone los frutos de su investigación hispana.

\subsection{Los escritos de la primera época: The Criterion (1922-1926)}

Un total de dos escritos, distantes año y medio en el tiempo, protagonizan la época inaugural de Criterion.

El primero es el previamente mentado "The Moors in Spanish Music", publicado en febrero de 1924. Es el más extenso de todos, no se incluye en una sección específica, y se puede definir como un ensayo, dividido en ocho partes, que aborda el tema del componente árabe en la música española.

Trend se refiere a él en más de una ocasión en la correspondencia con Falla. En una carta fechada el 9 de noviembre de 1923 le comenta lo que sigue:

“Tengo un estudio bastante extenso que empiece [sic] con el Cante jondo del año pasado (The Criterion), otro sobre la música en Galicia (Music \& Letters) y un artículo para The Musical Bulletin en donde se habla de usted"26.

26 Dennis, Nigel, ed.: Manuel de Falla - J. B. Trend. Epistolario (1919-1935), op. cit., p. 74. 
Y en carta del 26 de noviembre de 1923 añade:

“Otra cosa mía, hablando de usted y de Cante jondo y los límites de la 'Morisma' en la música española va a aparecer más tarde en el Criterion" 27.

El punto de arranque del ensayo es la celebración en el verano de 1922 del festival de música de Granada organizado por Manuel de Falla; Trend estuvo allí presente ya que lo cubrió como corresponsal para el Times y The Nation and The Athenaeum. De este modo, toda la primera parte se centra en la reproducción del recuerdo -no exento de cierta nostalgia- del festival (el hechizo de la noche, la Plaza de los Aljibes, el Darro, los jardines, el Albaicín, los decorados de Zuloaga y el encanto del público granadino, engalanado para la ocasión), y en la explicación del objetivo que llevó a Falla a la organización del evento:

"D. Manuel de Falla [...] had come to the conclusion that the traditional songs of Andalucía were usually heard in a degraded form and sung in a manner not in accordance with the true style; he had conceived the idea of a singing competition to provide examples of what the pure style was and to prevent it from being forgotten" 28 .

A partir de aquí despliega las siete partes restantes, en las que expone una serie de ideas derivadas de una hipótesis inicial, que no es otra que afirmar que la influencia árabe en la música española se encuentra en la interpretación más que en la música en sí:

“The 'orientalism' of Cante hondo is mainly on the surface; it lies in the manner of performance rather than in the music itself" 29.

Justifica su hipótesis comparando la música con las demás artes de España y analizando la impronta que en ellas dejó lo oriental; pero antes, comienza por el principio, y el principio en este caso es explicar al lector inglés el origen de la indudable presencia de un componente árabe en la cultura española.

Para ello, Trend se remonta a la invasión del 711 y, haciendo gala del resultado de sus investigaciones, habla de los diferentes músicos de la época, de los instrumentos, de las cantantes, del famoso método "El Farabî" del profesor de Toledo Aben Firnâs, e incluso de la presencia de instrumentos árabes en la literatura del Arcipreste de Hita. El musicólogo nos sorprende a continuación al exponer que, en contra de lo que parece, no existe evidencia clara de cómo fue el arte musical de aquel periodo histórico, de resultas

27 Íbid., p. 76.

28 Trend, J. B.: "The Moors in Spanish Music", en The Criterion, II/6 (1924), p. 204.

29 Íbid., p. 207. 
de lo cual no es un despropósito pensar que la huella oriental en las melodías de la Península provenga de un momento anterior a la invasión árabe ${ }^{30}$.

Es a partir de esta idea cuando se introduce en otras disciplinas, valiéndose en concreto de una extensa comparación entre la música y la arquitectura para validar la afirmación previa. Porque de igual modo que el arco de herradura fue probablemente una herencia visigoda heredada a su vez por los árabes, que tendieron a exagerarlo en las construcciones hispanas, es posible que diversas formas musicales preexistentes fueran adoptadas y ornamentadas por el pueblo musulmán; no en vano -y Trend menta en este momento a sus maestros- Falla cree que la Siguiriya gitana tiene mucho en común con el canto de la liturgia bizantina, y Pedrell afirma que los árabes únicamente se limitaron a modificar en las partituras ciertos rasgos ornamentales, comunes al sistema melódico persa y oriental ${ }^{31}$.

Siguiendo su comparación con la arquitectura, un último apunte apoya su hipótesis: el arte mudéjar, esto es, la asimilación por parte del pueblo árabe de la organización cristiana. El mudéjar, más que un estilo, es un método, asegura Trend con precisión; los estilos entonces vivos eran el románico y gótico, que en la Península se vieron enriquecidos con la detallada ornamentación del "método mudéjar". Algo similar ocurrió en las catedrales españolas cuando comenzaron a cantarse los himnos religiosos con una ornamentación alejada de su propia naturaleza, es decir, con una ornamentación acorde -permítase la licencia, en consonancia con el término artístico- al método "mudéjar". En definitiva, el profuso ornato que experimentó la música, fue compartido con todas las manifestaciones artísticas de la Península. ¿Herencia oriental? Sí, pero no en la creación en sí sino en el modo de interpretarse:

"The Moorish contribution to Spanish music, then, is the Mudéjar style, that is, a scheme of decoration rather than a type of construction. It is the manner of performance which is oriental rather than the music itself" 32 .

El contenido de esta primera colaboración sirvió a Trend para dar forma, dos años después, a las páginas iniciales del ensayo The Music of Spanish History to 1600 (1926); en concreto, en la "Introduction" del volumen recoge las dos primeras partes del artículo; en el capítulo I, titulado "The Moors", las partes tercera y cuarta, y en el capítulo II, titulado “The Moors (continued)", las partes quintas, sexta y séptima. Salvo por algunas variaciones, los textos son prácticamente iguales ${ }^{33}$. Es ésta conducta habitual entre los estudiosos, con lo que hasta aquí nada habría que objetar a Trend. La objeción comienza cuando descubrimos que el autor emplea párrafos exactos del mismo artículo en otro de sus trabajos, en concreto, en un libro de viajes titulado Spain from the South de 1928. En esta ocasión, Trend reproduce en el capítulo inicial de la obra, dedicado a "Algeciras and Ronda", varios parágrafos del escrito, que explican el sentido y significado del cante jondo ${ }^{34}$.

30 Íbid., p. 213.

31 Íbid., p. 214.

32 Íbid., p. 219

33 Trend, J. B.: The Music of Spanish History to 1600. Oxford, Oxford University Press, 1926, pp. 1-37.

34 Trend, J. B.: Spain from the South. London, Methuen \& Company, 1928, pp. 11-12. 
El cante jondo y el aire oriental también están presentes en la segunda colaboración de la primera época de Criterion, aunque desde un punto de vista diverso al previo. Se titula "Music. The Spanish Idiom" y aparece seis entregas después en la ya creada sección fija "Music" del número 12, de julio de 1925. Como sabemos, las publicaciones de Trend en Criterion desde este momento serán más breves que la primera colaboración y perseguirán dar a conocer a los lectores de la revista el panorama musical europeo (español, en nuestros textos) o simplemente opinar sobre un tema concreto al respecto.

Si en "The Moors in Spanish Music", el autor partía del festival de 1922 para adentrarse en el estudio sobre la influencia árabe en la música española, en esta segunda colaboración, la anécdota inicial es -y valga la expresión- bastante más anecdótica. Afirma Trend que muchos melómanos ingleses le aseguran estar cansados del así dicho "Spanish idiom"; el autor, ante tal escepticismo, va a intentar explicar a sus paisanos el sentido del término para desmitificarlo después.

No resulta fácil traducir al castellano esta expresión: el modismo español, el aire español, el tono español... Llamémosle como lo llamemos, lo cierto es que el Spanish idiom vendría a ser el particular carácter de la música de nuestro país que la identifica como española, y que en Inglaterra tiende a asociarse con la música del sur, la del flamenco y las castañuelas. Dicho de otro modo, el gran error del público inglés se encuentra en haber identificado el "Spanish Idiom", con el "idiom of Andalucía, degraded by gipsies, and still further debased by composers of popular songs" 35 . Este es el tópico, el cliché, que Trend quiere desarmar a los ojos británicos, introduciéndoles en las melodías de las diversas regiones españolas, y particularmente en las de Cataluña.

La música catalana nada tiene del británico Spanish idiom, asegura Trend: diferente idioma y acentuación, menos pasión pero más claridad musical y ni asomo de la cadencia frigia que caracteriza al cante hondo. Para explicarlo, Trend acude, al igual que había hecho en el primer escrito con la impronta árabe, al origen de esta arte en la región:

"the words are often ballads or old legends such as 'Comte l'Arnau' and 'La Dama d'Aragó' [...]. Others relate to historical persons or events, such as Don Juan de Serralonga, the famous seventeenth-century robber, the civil war of the Segadors, and the War of Spanish Succession, in which the Catalans, like the English, were on the losing side. Others again are religious, or pastoral like the delightful 'Pastoret, bon pastoret', the rhythm of which would be given by the words 'There goes the boy, looks after the sheep"'36.

Aparte de remontarse a los inicios, Trend vuelve también sus ojos a dos músicos contemporáneos, catalanes de origen, empeñados en el intento de "destopizar" el tópico: por un lado, Enrique Granados,

35 Trend, J. B.: "Music. The Spanish Idiom”, en The Criterion, III/12 (1925), p. 567.

36 Íbid. 
quien ha creado un arte repleto de modernidad ante el resto de Europa, combinando la influencia del siglo XIX alemán, de Listz y la esencia musical -y nos topamos aquí con el concepto de tradición- de otras épocas y regiones:

"Granados, with his alert Catalan intelligence, was quick to seize upon the essential qualities of the music of other times and other regions. He arranged [...] some of the harpsichord sonatas of Domenico Scarlatti, who through his long residence in Spain is regarded as the founder of Spanish pianoforte style; and he composed several books of Tonadillas, in the manner of eighteenthcentury Spanish songs" 37 ;

y, por otro, Isaac Albéniz, un catalán de origen que, si bien se decanta por el aire andaluz en su música, lo emplea con tal maestría que no abruma la partitura. ¿Y el internacional Falla?, se pregunta el comentarista a continuación. Gaditano ilustre, en piezas como el Retablo de Maese Pedro (especialmente familiar para Trend pues la tradujo al inglés), se aleja de la impronta de su tierra para evocar, por el contrario, el espíritu de la austera Castilla. Significativos ejemplos que sirven al crítico para culminar recomendando al escéptico público inglés no hablar de un Spanish idiom sino de tantos como regiones tiene España.

El título “The Spanish Idiom” es también el elegido para el capítulo segundo del ensayo Manuel de Falla and Spanish Music, de $1929^{38}$. Ante tal coincidencia se podría pensar que las páginas de Criterion quedaron después recogidas en el volumen; sin embargo, los textos no coinciden en su totalidad, ya que el capítulo del libro tan solo reproduce literalmente un tercio del artículo (la sección dedicada a Granados y Albéniz), que se sitúa en la parte final. El capítulo queda completado con un primer tercio en el que Trend habla del cante hondo (con ideas similares a las expresadas en "The Moors in Spanish Music", aunque esta vez, con redacción modificada), y un segundo tercio intermedio, que es la reproducción casi exacta de una buena parte de "Music. Spain and Hungary", la siguiente colaboración con aire español que Trend publica en The Criterion, que a continuación se pasa a analizar.

\subsection{Los escritos de la segunda época: The New Criterion. A Quarterly Review (1926-1927)}

La segunda es la etapa más rica en nombres musicales españoles: tres escritos dedicados al tema en tres entregas sucesivas del año 1926.

Trend publica el primero de ellos recién estrenados nombre y época, dos números después del anterior; como acabamos de señalar, lleva por título "Music. Spain and Hungary" (enero de 1926). En

37 Íbid., p. 568.

38 Trend, J. B.: “The Spanish Idiom”, en Manuel de Falla and Spanish Music, op. cit., pp. 15-35. 
él vuelve a un tema reiteradamente estudiado en su producción: el renacimiento musical en diferentes países europeos gracias a la recuperación de melodías del pasado, del folklore, de la tradición.

La edición de un número especial de la revista L'Esame dedicado al trabajo de los compositores del momento es esta vez el dato concreto con el que Trend empieza su exposición. La publicación ha limitado su elenco a creadores de Reino Unido, Francia, Alemania y Rusia, dejando fuera a dos nombres, según él, fundamentales y muy respetados, además, en Inglaterra: el español Manuel de Falla y el húngaro Béla Bartók. Si echa de menos su presencia en la publicación es precisamente por lo anunciado: porque considera indudable su contribución al renacimiento musical que contempla Europa gracias a la recuperación de genuinas canciones populares. A partir de aquí desarrolla su artículo, centrándose en esta idea.

Antes de detenerse en cada compositor, se remonta de nuevo a los orígenes, en este caso, a la herencia oriental en sus respectivos países, mayor en el caso de España, lo que desde un punto de vista musical se aprecia en un diferente uso de la instrumentación, mucho más austero en la música húngara, mucho más ornado en la hispana. Recuérdese que ya quedó explícita en el primer escrito de Trend la idea de que el influjo oriental dejó su huella en la interpretación y no tanto en la composición en sí; en este sentido, explica ahora, la música española es bastante más exagerada que la húngara, aspecto este acentuado por el particular carácter otorgado por los intérpretes gitanos:

"The Muslim contribution to Spanish music was a manner of performance rather than a type of construction, a manner which has always been exaggerated by gipsy performers, and which exceeds anything to be found in the Hungarian melodies published by Béla Bartók"39.

Es aproximadamente en el segundo tercio del artículo, cuando Trend alude a los maestros, a quienes les une su duro esfuerzo "to disinter the older forms of melody, as they were before the vulgarization which set in at the beginning of the last century"40.

La causa de esta vulgarization a principios del siglo XIX encuentra su explicación en una llamémosle "gitanización" de las formas, esto es, en la popularización de las melodías por el modo de hacer de los intérpretes gitanos y -algo más grave- en la imitación de este forma de interpretación gitana por músicos payos. ¿La causa de este fenómeno? En España, Trend no lo duda: el movimiento romántico que así lo fomentó.

Falla y Bartók no se han opuesto al uso de los tonos populares; sencillamente los han empleado a su manera:

39 Trend, J. B.: "Music. Spain and Hungary", en The New Criterion Iv/1 (1926), p. 156.

40 Íbid. 
"have each achieved a very definite musical individuality, by going through a course of folk song, and, as it were, coming out on the other side" ${ }^{41}$; y, como ellos, el inglés Vaughan-Williams. A los tres les une una austeridad en sus composiciones, desconocida en sus contemporáneos, y una gran riqueza en las posibilidades de expresión, todo ello motivado por el simple hecho de haber acudido al folklore de su país:

"The fact is that, at the present moment, a composer of real originality who has trained himself upon the folk songs of his native land, has wider possibilities of expression than one who has not done so; and the paradox follows, that, while this music is apparently written in the musical language of one country, it is yet the kind of music which, owing to its sincerity, makes an immediate and unmistakable appeal to an international audience" ${ }^{42}$.

Trend se reserva la parte final del escrito para su admirado Falla. Y en este caso su particular alabanza ahonda en la sensibilidad del gaditano en el empleo de la tonalidad -más convencional que en el húngaro-, y en su maestría en el manejo de los ritmos - a veces violentos- en los que se ve la huella oriental de la interpretación. Todo ello le da pie a Trend para culminar volviendo a su tesis largamente repetida: el rastro árabe en la música de Falla es herencia de los musulmanes y gitanos hispanos no tanto en las melodías sino en el modo de interpretación.

De la mano de esta idea reincidente, llegamos en el siguiente número de The New Criterion, de un trimestre después (abril 1926), a "Music. Musicians and Philosophers". Al contrario de su costumbre, la anécdota que motiva el escrito no viene dada desde el principio; esta vez comienza mucho más bruscamente, espetando al lector la afirmación de que entre músicos y filósofos existe una clara falta de entendimiento: hablan diferentes idiomas, se expresan con distintos términos; el primero tiene más de psicólogo, y el segundo, más de matemático. El problema es que el filósofo "is confused and puzzled when he hears musical things expressed in terms of the other arts"43.

El caso es que dos filósofos latinos se han metido momentáneamente a críticos musicales: el español José Ortega y Gasset y el italiano Fernando Liuzzi, con "Musicalia” (El espectador, III, 1921) y La deshumanización del arte, y con Música latina y música alemana respectivamente. Y como cabe imaginar, la en este caso crónica de Trend se centra en la crítica de las obras, si bien -y esto es lo realmente interesante- acaba hablando de la música española del siglo XVI. ¿Cómo? A partir de la creación de Ortega, a quien le dedica el mayor número de líneas y con quien no resulta muy benévolo (algo, por otra parte, no demasiado extraño pues no fue la primera crítica que Ortega recibió al respecto):

41 Íbid., p. 157

42 Íbid., pp. 157-158.

43 Trend, J. B.: "Music. Musicians and Philosophers", en The New Criterion, Iv/2 (1926), p. 343. 
"Sr. Ortega, one feels, has not been altogether well advised in his choice of contemporary music. His book contains some brilliant things; but his musical experiences seem to have been confined to Debussy and Stravinsky, with a passing reference to Ravel. Neither Schönberg nor Bartók, Malipiero nor Casella, nor even his own countryman, Falla, are so much as mentioned"44.

No desprecia el mérito de la teoría de la deshumanización pero considera que no aporta nada nuevo:

"indeed the history of Western music might be described as a series of oscillations between 'humanization' and 'dehumanization"”45.

Trend destaca el extracto en el que el autor se muestra crítico con Wagner para compararlo después con Debussy: el del alemán es un arte radical, subjetivo y demasiado humano, opina el filósofo; la música del francés, por el contrario, se diluye serena y ajena a los sentimientos específicos del creador; es decir, según Ortega, Debussy no se vale del arte para mostrar su yo; o lo que es lo mismo, Debussy deshumaniza la música.

Trend disiente en la opinión sobre Wagner aunque coincide respecto a Debussy, pero no sin apostillar que el francés no es en absoluto novedoso pues en la propia España, Tomás Luis de Victoria ya había compuesto música deshumanizada tres siglos atrás en el tiempo. Es en este momento cuando el comentarista ha sucumbido ante el musicólogo, y lejos del tema fundamental del escrito, Trend deriva hacia nuevos derroteros que le conducen hasta el músico del siglo xvi. Victoria -explica- se dio a conocer en Roma gracias al expresivo realismo de su música, pero con sesenta años cambió su estilo deshumanizándolo: escribió desde entonces piezas de música litúrgica para gran número de voces tratadas sinfónicamente, en las que introducía asimismo y por contraste, expresivos pasajes compuestos a la antigua manera. De este modo:

"[...] the whole effect is not the expression of the words, but a marvellous volume of sound, in which the words are little more than syllables for the voices to sing" 46 .

Llegamos así a la siguiente aportación de Trend al mundo español, con el escrito publicado en la entrega sucesiva (de junio de 1926) de The New Criterion, titulado "Music. A Contemporary of the Tudors”. Está dedicado íntegramente al compositor español Cristóbal de Morales.

Como en la muestra anterior, parte de una reciente publicación, en este caso de The Problems of Modern Music, la versión inglesa del ensayo del profesor alemán Adolf Weissman, con traducción

44 Íbid., p. 345.
45 Íbid.
46 Íbid., p. 347. 
y prólogo de E. J. Dent, el maestro de Trend. Y como en muestras anteriores reitera la idea de la agitación que el arte musical está viviendo en los tiempos modernos gracias a la recuperación de la tradición, opinión compartida por los tres. La peculiar aportación del libro de Weissman se encuentra precisamente en su profundo análisis de estos antecedentes, remontándose a los compositores de la llamada "Música Tudor".

Éste es el obligado preámbulo porque a partir de aquí Trend abandona la obra del alemán para comenzar la exaltación de Morales, al que sitúa a la altura de Palestrina, Orlando de Lasso, Victoria y Marenzio. Tras adentrarse en datos necesario para entender la música del siglo XVI (su escritura, sus soportes, etc.) e introducir una breve digresión que aclara la dificultad de investigación en este campo así como un par de anécdotas personales de su periplo por bibliotecas españolas, comienza a desgranar la trayectoria del compositor para centrarse en sus innovaciones, sobresalientes entre sus contemporáneos.

Afirma primero que la música de Morales contó con ras gos particulares que la distinguieron de la de sus maestros los flamencos, tales como "the disposition, the 'spacing' of his voices, and his use of massive declamation by all the voices at once when the words gave particular point to the music" ${ }^{47}$, así como una aguda comprensión de las posibilidades de ciertos giros melódicos que se han convertido en punto de referencia no sólo antaño sino también en la actualidad:

"A constant feature of Southern Spanish popular music of today - the pianoforte pieces of Albéniz and Granados are full of it- is the perpetual recurrence of four descending notes, with a drop of semitone on the bottom one" ${ }^{\prime 4}$.

Continúa asegurando -para lo que acude a la opinión del maestro Pedrell- que es este recurso el que concede a la música de Morales, además de una honda expresividad, un sabor intensamente español, algo similar a lo que ocurrió con sus contemporáneos europeos que también llenaron sus partituras de la idiosincrasia propia de su país. Y como sus contemporáneos, Morales tampoco dudó en romper ocasionalmente las normas de contrapunto, en un nuevo reto en la senda musical:

"What strikes one particularly is his imaginative use of structural principles. He does not make wild shots and lucky hits like Taverner; but if he is less surprising than his English contemporaries, he always seems to know exactly what he is doing"49.

47 Trend, J. B.: "Music. A Contemporary of the Tudors", en The New Criterion, iv/3 (1926), pp. 566-567.

48 Íbid., p. 567.

49 Ibid. 
Y finaliza esgrimiendo que si bien la preocupación formal y la austeridad lo definieron como músico, también estas cualidades le provocaron, como contrapartida, la destitución del servicio de la iglesia romana en favor de Victoria. Sin embargo, "it was Morales who showed musicians in Rome, the centre of the musical world, how that development might be accomplished" 50 , añade Trend.

Por todo ello, se lamenta en la parte final del artículo, "the music of Morales might be better known" ${ }^{51}$. Reivindica su arte, en la actualidad casi olvidado: ni Palestrina, ni Orlando Lasso, ni Marenzio; simplemente, Morales, el mejor compositor europeo en el momento de su muerte. Coetáneo a los primeros compositores Tudor -a Taverner, Tye y Tallis-, como ellos, gozó de una personalidad musical flamenca, y, como ellos, dotó a la música de una impronta propia sin olvidar, sin embargo, el camino marcado por los maestros:

"Neither old English music, nor old Spanish music, can be studied in a water-tight compartment, all by itself. The Flemish musicians, and then the Italians, both had their share in moulding it" 52 .

Un guiño, de nuevo, a la siempre presente tradición.

\subsection{Los escritos de la cuarta época. The Criterion. A Literary Review (1928-1939)}

Como ya se mencionó, durante el Monthly Criterion o tercera época de la publicación, Trend no firma ningún texto que se vincule con la música española. La revista tiene que convertirse otra vez en The Criterion para que el escritor dedique nuevas referencias a nuestro país. El nombre de la sección ha pasado de ser "Music" a "Music Chronicle", y dentro de ella son dos las colaboraciones hispanas de Trend, ambas en 1929 (cerca de tres años después de la última) y en números casi sucesivos: la

primera lleva por título "Music Chronicle. Falla and the Ballet" ( $\mathrm{n}^{\circ} 32$, abril 1929) y la segunda, "Music Chronicle. The Present State of Contemporary Music" (n³4, octubre 1929).

Dado el nuevo nombre de la sección, cabría imaginar que los escritos de esta cuarta época fueron verdaderas crónicas del panorama musical del momento; muy al contrario y para nuestra decepción, el método por Trend utilizado sigue siendo el habitual, esto es, arrancar del dato concreto inicial para luego desplegar un discurso con claro carácter ensayístico. El cronista, por tanto, brilla por su ausencia; es más, el musicólogo, al igual que en colaboraciones previas, emplea estas falsas crónicas como capítulos de Falla and Spanish Music: la primera dará vida a los capítulos VI y VIII, titulados -claro"El amor brujo" y "The Three-Cornered Hat", y la segunda al capítulo XII titulado "Falla and his

50 Íbid., p. 569.

51 Íbid., p. 568.

52 Íbid., p. 569. 
Contemporaries" 53 . Surge, sin embargo, la duda: puesto que volumen y artículos se publicaron todos en 1929 ¿no sería que Trend convirtió, por el contrario, los capítulos en falsas crónicas para Criterion? Posiblemente, pues es fácil intuir que aprovechara lo creado para el monográfico para cumplir con dos de las citas con la revista. Sea como fuera, analicemos brevemente el contenido de ambos escritos, como venimos haciendo hasta ahora.

Es fácil intuir que el contenido de "Music Chronicle. Falla and the Ballet" tiene como referente las partituras del español, en este caso sus dos grandes ballets: El sombrero de tres picos y El amor brujo. Como paso previo a ellos, el escritor ha introducido al receptor en su texto a partir de la habitual anécdota, que ahora se cifra en la reaparición en Londres en enero de ese año del gran director suizo M. Ernest Anserhe, precisamente quien condujo la primera representación de El sombrero de tres picos en 1919 en Granada con la compañía de ballet rusa Diaghilev.

En un gran flash back de años en el tiempo, revisa primero la situación de la citada compaña (define a la actual como la era post-Diaghilev) para centrarse después en el análisis de ambos ballets, especialmente en El amor brujo. En concreto, gira su vista a París, a la puesta en escena llevada a cabo por Antonia Mercé, La Argentina. Trend no da referencias concretas de la representación pues ya sabemos que no son los datos lo que le interesa; lo que en verdad le interesa es alabar el espectáculo $\mathrm{y}$, sobre todo, transmitir su magia y sentido a un lector inglés desconocedor de la pieza (El amor brujo "has never been seen in London" ${ }^{4}$, añade).

Sin duda, la nota dominante del escrito es el entusiasmo - ¿excesivo?- con el que lo redacta; queda patente en algunos extractos que a continuación reproduciremos. Por ejemplo, ensalza a La Argentina por su comprensión del arte de la danza en la pieza, cuyos visibles movimientos -explica Trend- deben fundirse con el movimiento invisible de la música. Ella, como bailarina y directora, ha logrado esta unidad y no hay detalle que se le escape: cada ademán, cada gesto corporal, alcanza la perfección. El autor lo ejemplifica con la efectista aparición del espectro, que describe con palabras cargadas de misterio:

"The ghost must appear as if from nowhere. A moment ago he was not there. Three sighing chords on the strings and an agitated phrase for muted trumpet, and there he stands, with a green phosphorescent light on his unshaven chin -as if he had just come out of his grave and had brought his own glow-worms with him. There must be no suggestion of his 'walking on', and being picked up afterwards by a green spot-light. These things must happen as if by magic -they must happen, that is, by music"55.

53 Trend, J. B. "El amor brujo", en Manuel de Falla and Spanish Music, op. cit., pp. 79-91. ID.: "The Three-Cornered Hat", en Manuel de Falla and Spanish Music, op. cit., pp. 102-112. ID.: "Falla and his Contemporaries", en Manuel de Falla and Spanish Music, op. cit., pp. 158-179.

54 Trend, J. B.: "Music Chronicle. Falla and the Ballet", en The Criterion, viII/32 (1929), p. 482.

55 Íbid., p. 484 
Se detiene después en la propia música haciendo especial énfasis en su carácter español, creado por Falla a través de una combinación de ritmos marcadamente andaluces que alterna, contrasta y enfrenta. El interés del "cronista" recala en la "Danza ritual del fuego", en su dinámica expresividad, conseguida por medio de la inclusión de una recurrente figura en el bajo: cuatro notas con diferente acento, de las cuales "the third one has a much heavier accent than most pianist and conductors ever give it”. Y añade, con palabras cargadas ahora de contenido entusiamo:

"A thing which neither a pianoforte nor a concert performer can give, however, is the harsh, piercing, barbaric cry of the haunted Candelas and her dancers, first on the 'off' beats, and then on the 'off' bars. Listening to that, in Paris, one feels the city crumble to dust"

La contención va desapareciendo y cede su vez a una acentuada emoción, que lleva a Trend a un ensalzamiento de lo hispano, no demasiado acorde con la visión europeísta de la cultura que defiende Criterion:

"Where is the boasted mundo latino, the 'defence of the west' or, for that a matter Europe itself! If Falla is latin in this, he is like a Latin writer -like Apuleius, for instance- using the Latin language to describe utterly un-Latin things. Away with all this Latin sophistication!" 57.

Y de la acentuada emoción llegamos finalmente a un Trend extasiado que sucumbe en el colofón de la obra, con la inminente caída del telón: los fantasmas se desvanecen, se escuchan las campanas de la mañana, y "we find ourselves standing up along with our neighbours, clapping our hands sore and shouting ourselves hoarse".

Es entonces cuando, ante el delirio del público:

"La Argentina, recalled again and again, moves forward with her incomparable grace; she holds out her arms to Falla in the wings, but he steadily refuses to appear. The curtain descends for the last time; we rub our eyes wonder where we are. Grim and fantastic as the story of El amor brujo is, wild and barbaric as is the music, it has not sounded exotic but natural -the natural expression of a natural course of events; and only the keenest sense of musical form and logic can make such seem that" $"$.

Con tan emotivas palabras nos introducimos en el último de nuestros escritos. Dista mucho del anterior pues si aquél se centraba desde el principio en el compositor de Cádiz, este arriba a España

56 Íbid., p. 485.

57 Íbid.

58 Íbid., p. 486. 
a partir de un análisis de la situación de la música en Europa. No en vano el escrito lleva por título "Music Chronicle. The Present State of Contemporary Music"59.

Su germen se encuentra en dos libros: el amplio volumen ilustrado Handbook of Musical Knowledge de Hans Mersmann, publicado en Postdam, y The Listener's History of Music (Oxford University Press) de Percy Acholes; ambos estudian el valor del arte musical con respecto a las demás artes. Trend en este sentido expresa su convencimiento, en contra de los argumentos defendidos en sendos ensayos, de la necesidad de un análisis de la música contemporánea, centrado única y exclusivamente en sí misma.

Tras una digresión sobre este asunto, que se detiene en el peso de la "street-music" en la creación española (que es, según Trend, la que dota a las melodías españolas de un aire -tono, modismo- propio; a vueltas, de nuevo, con el Spanish idiom); tras esta digresión, decíamos, el autor analiza, obediente al título del escrito, el panorama de la música actual país por país, sin escatimar la crítica cuando ésta es necesaria.

Con un metafórico código asociado al mundo de los antiguos exploradores que mantiene hasta el final del escrito, habla primero de Schönberg y su grupo, de quienes dice que se han extraviado totalmente; su inicial espíritu pionero de exploración, que mereció todo el crédito y la admiración de crítica y público, parece haber terminado en un profundo valle del que no hay salida posible. Continúa con el "Estilo Armisticio" -ya mencionado en el comentario previo- ejemplificado en el grupo francés de "los Seis" y los ballet rusos, a quienes califica de pasados de moda; "Honegger alone has survived as a serious musicians, and he is not French but Swiss" ${ }^{60}$, añade. Tilda, por el contrario, de carente de originalidad e innovación al estilo Auric-Poulenc-Milhaud y a un desertor Stravinsky que hasta entonces había destacado por la seriedad de sus partituras.

Sigue su itinerario con la mucho más acertada música de países como Alemania, (con Jarnach, Krenek, Kurt Weill, Paul Hindemith y Max Butting), Inglaterra, Francia, Italia, Checoslovaquia, Suiza, Holanda, Dinamarca, Polonia, y Estados Unidos, sin olvidarse del jazz. Y finaliza aludiendo al estilo neoclásico italiano, liderado por Casella. Sus seguidores han tomado como modelo de música moderna el "Pulcinella" de Stravinsky, que ha derivado en diversas formas sin demasiado sentido, ni atisbo de desarrollo, ni mucho menos, ansia de exploración de nuevos caminos:

"They are the movements not of pioneers but of tourists, who ascend well-known peaks by well-worn tracks, or even by a funicular railway" ${ }^{\prime}$.

Pero en medio de toda esta confusión de caminos entrecruzados, añade el autor en la parte última del escrito, el panorama europeo encuentra una gran luz en Manuel de Falla:

59 Muchas de las ideas que aparecen en este escrito y en el anterior protagonizan las cartas entre Trend y Falla de julio de 1928. En ellas se alude al Pulcinella de Stravinsky, a la compañía Diaghilev, a Honneger, etc. (Dennis, Nigel, ed.: Manuel de Falla- J. B. Trend. Epistolario (1919-1935), op. cit., pp. 158-159).

60 Trend, J. B.: "Music Chronicle. The Present State of Contemporary Music", en The Criterion, IX/34 (1929), p. 99.

61 Íbid., p. 100. 
"Falla arrived exactly at the right moment. The ballet, 'The Three-Cornered Hat', saved the musical reputation of the Russian Ballet. Falla's music gave everyone the chance of becoming acquainted with the tendencies of contemporary composers. His methods sometimes reminded the audience of Stravinsky, Bartók or Vaughan Williams; but they seemed to be more immediately accessible, while the boldness of his design and the vigour of his rhythm never left his meaning in doubt"62.

Como se puede apreciar en estas palabras, el entusiasmo del artículo anterior no sólo se ha mantenido sino que ha ido in crescendo en el actual. Aun siempre querido y ensalzado por Trend, en estos dos últimos textos Falla es tratado con cierta sobredosis de admiración que raya la -merecida o no-imparcialidad. La explicación a esta actitud se encuentra en que en esos momentos Trend publica también su monográfico sobre el compositor y, por consiguiente, se halla especialmente cercano a su obra y a su persona, con la que lleva ya andada, no lo olvidemos, una correspondencia de diez años. El maestro gaditano, que había abierto en 1924 la senda española en las colaboraciones del inglés en Criterion, la cierra ahora, un lustro después, con gloria sobrada. Buen colofón para un adiós definitivo porque, aunque el musicólogo seguirá escribiendo en Criterion hasta el 33, reiteramos que en los comentarios que restan no hay de nuevo evidencia de nuestra cultura.

\section{Conclusiones}

Expuesto el contenido de los escritos, bien se puede ahora volcar unas conclusiones finales. Lejos de ser innumerables, se limitan a tres: inicialmente, la constancia de que desde el artículo inaugural del 24 hasta la última colaboración del 29, se repiten una serie de ideas reincidentes; a continuación, la evidencia de que todos los caminos llevan a Falla y al concepto de tradición, ambos relacionado entre sí, y vinculados asimismo con Eliot y el espíritu de The Criterion; y finalmente, la comprobación de de que estas ideas son o serán las recogidas en sus volúmenes de ensayos.

Comencemos enumerando esa sucesión de nociones reiterantes. La primera se refiere al componente oriental en la música española, apreciable en el ornato en la interpretación de las partituras. Esta idea inspira "The Moors in Spanish Music", el escrito inicial, y asoma de nuevo en "Music. Spain and Hungary", escrito de la segunda época; unida a ella, Trend defiende -como Falla- la obligación de recuperar la austera autenticidad del cante hondo, presente también en ambos artículos.

La segunda se asocia con la necesidad de destronar la identificación de la música española con la música flamenca o, dicho de otro modo, de destronar la idea de que el carácter español es sinónimo del carácter andaluz; en España existen tantos aires musicales como regiones, defiende enérgicamente

62 Íbid., p. 102. 
Trend en "Music. The Spanish Idiom", la segunda de las colaboraciones. Esta fue la gran lucha de Trend con sus paisanos, hay que añadir.

La tercera no es otra que la recuperación de las figuras musicales de siglos pasados (como Victoria y Morales) y la necesidad de hacer justicia a Felipe Pedrell; a la música del siglo XvI va dedicada "Music. A Contemporary of the Tudors", de igual modo que de soslayo aparece aludida en "Music. Musicians and Philosophers", ambas de la segunda época.

La cuarta enlaza con la anterior, pues se refiere a la reivindicación de la tradición musical, es decir, de la herencia de un pasado, necesaria para la creación de la música del presente, permanente en un futuro; queda patente en la mención a Granados en "Music. The Spanish Idiom”, en el elogio a la labor de Falla en "The Moors in Spanish Music", en el porqué de la grandeza de la música contemporánea húngara y española en "Music. Spain and Hungary", y en el escrito dedicado a Morales, por motivos evidentes.

La quinta y última: Manuel de Falla, presente en todos los artículos, especialmente en los tres primeros y en los dos últimos; en los iniciales la admiración es clara pero en los finales aumenta al ser presentado el creador como la luz de la música occidental. No le falta a Trend entusiasmo ni parcialidad, pero tampoco le falta lógica.

La lógica se encuentra -y estamos entrando en nuestra segunda gran conclusión- en que el compositor aúna todo lo anterior: aúna en sus partituras el aire español, andaluz y no andaluz, y la herencia del pasado con la modernidad del futuro. De este modo, la tradición es Falla; resulta así congruente introducir su constante alusión en The Criterion, la revista que nació -entre otros- a partir de este principio.

Recordemos que, además, este principio fue sugerido por el propio Trend en el prólogo de, precisamente, Manuel de Falla and Spanish Music. Allí vislumbró la definición de la tradición en semejanza con la vertida por Eliot en "Tradition and the Individual Talent". No es por tanto extraño - y atisbamos ahora nuestra última conclusión- que una buena parte de los escritos de Criterion dieran después vida al contenido del monográfico sobre el compositor. El propio Dennis así lo asegura:

"El interés del Trend crítico por la obra de Falla [...] culmina [...] en 1929 con la publicación de su libro Manuel de Falla and Spanish Music. Aunque se trata, en gran medida, de una recopilación de trabajos ya publicados..."63.

El estudioso no introduce en su cita referencias concretas, pero se puede confirmar que en este ensayo Trend bebe de la fuente de Criterion con los casos que se han ido mencionando a lo largo de estas páginas. Recapitulando, cuatro de los capítulos del libro (II, VI, VIII y XII) están creados a partir de cuatro de las colaboraciones de la revista: "Music. The Spanish Idiom" (1925), "Music. Spain and

63 Dennis, Nigel, ed.: Manuel de Falla - J. B. Trend. Epistolario (1919-1935), op. cit., p. 20 
Hungary" (1926), "Music Chronicle. Falla and the Ballet" (1929) y "Music Chronicle. The Present State of Contemporary Music" (1929).

La excepción en nuestro elenco de escritos se encuentra en los dos artículos centrales y en la colaboración inaugural. En los dos centrales -"Music. Musicians and Philosophers" y "Music. A Contemporary of the Tudors"-, Trend se detiene en Morales y Victoria, y Falla apenas es mentado. Son ambos del 26, en justa coincidencia con los trabajos que en esa época había publicado sobre este tema: Luis Milán and the Vihuelistas (1925) y The Music of Spanish History to 1600 (1926). En este caso los escritos de Criterion recogen ideas de las obras, pero no reproducen idéntica redacción.

En la colaboración inaugural "The Moors in Spanish Music" (1924), aun dedicada a Falla, no hay huella exacta de ella en el monográfico sobre el compositor (sí, alusiones a su contenido); posiblemente habría sido de otro modo si Trend no hubiera ya empleado este texto en dos obras previas a Manuel de Falla and Spanish Music: la citada The Music of Spanish History to 1600 (1926) y Spain from the South (1928).

En definitiva, la hipótesis inicial de este artículo pretendía probar un mayor o menor vínculo del contenido de los escritos de Criterion con la línea de la revista y la obra general de Trend. Como ha quedado demostrado, el vínculo es estrecho en ambos casos: en el primero, se crea gracias a la tradición y al propio Falla; en el segundo, gracias a la habilidad de Trend para reproducir textos similares o idénticos en diferentes soportes. La seña de identidad propia del autor en Criterion fue la anécdota inicial, un truco formal para dar al escrito un falso aire divulgativo que enlazaba con un discurso casi siempre utilizado previa o posteriormente. Terminemos dando la razón a Wilson porque Trend se repitió también en la revista de Eliot; por falta de imaginación, por falta de tiempo, porque es la práctica habitual o quizá porque sólo así pudo cumplir uno de sus grandes objetivos: dar a conocer una música hispana "deshispanizada" -con sus raíces, su variedad, sus maestros y su tradición- a un público inglés abrumado por el "Spanish idiom”.

\section{FUENTES}

Trend, J. B.: “The Moors in Spanish Music”, en The Criterion, II/6 (1924), pp. 204-219.

"Music. The Spanish Idiom", en The Criterion, III/12 (1925), pp. 564-569.

"Music. Spain and Hungary", en The New Criterion, Iv/1 (1926), pp. 154-160.

"Music. Musicians and Philosophers", en The New Criterion, Iv/2 (1926), pp. 342-349.

"Music. A Contemporary of the Tudors", en The New Criterion, Iv/3 (1926), pp. 563569.

"Music Chronicle. Falla and the Ballet", en The Criterion, vIII/32 (1929), pp. 480-486.

"Music Chronicle. The Present State of Contemporary Music", en The Criterion, IX/34 (1929), pp. 96-102. 


\section{Bibliografía CITADA}

Dennis, Nigel, ed.: Manuel de Falla - J. B. Trend. Epistolario (1919-1935). Granada, Universidad de Granada, Archivo Manuel de Falla, 2007.

Eliot, T. S.: "The Function of a Literary Review, en The Criterion, I/4 (1923).

"The Idea of a Literary Review", en The Criterion Iv/1 (1926).

Selected Essays. London, Faber \& Faber, 1999.

ELIOT, Valerie, ed.: The Letters of T. S. Eliot. Volumen 1: 1898-1922. London, Faber \& Faber, 1988.

Gallego Morell, Antonio: "Música en la universidad”, en ABC, (8 de enero de 1960).

SAlinas, Pedro; y Guillén, Jorge: Correspondencia. 1923-1951. Barcelona, Tusquets, 1992.

Trend, J. B.: A Picture of Modern Spain: Men \& Music. London, Constable \& Company, 1921. Spain from the South. London, Methuen \& Company, 1928. Manuel de Falla and Spanish Music. New York, Alfred A. Knopf, 1934. The Music of Spanish History to 1600. Oxford, Oxford University Press, 1926.

Wilson, Edward M.: “John Brande Trend”, en Bulletin of Hispanic Studies, Xxxv (1958), p. 223.

Recibido: 03/03/2008

Aceptado: 27/10/2008

Consultar Fe de erratas en la siguiente página

Please see the Corrigendum on the next page 


\section{FE DE ERRATAS}

En la versión impresa del artículo:

Garbisu Buesa, Margarita: "La recepción de la música española en The Criterion a través de los escritos de John B. Trend”. Anuario Musical 63: 153-180, (2008),

la dirección de Anuario Musical hace constar las siguientes erratas:

Páginas 153, 155, 158, 162 y 180 [15 de enero de 2010]: el nombre del hispanista inglés 'Edward M. Wilson' se cita erróneamente como 'Edgard M. Wilson'.

Página 174 [29 de marzo de 2010]:

línea 10, donde se lee "M. Ernest Anserhe" debería leerse "Ernest Ansermet" línea 11: donde se lee "en Granada" debería leerse "en Londres"

Estas errata han sido corregidas en esta versión electrónica del artículo en las fechas que figuran entre corchetes.

La correspondiente fe de erratas se incorporará en el próximo número de la edición impresa de la revista. Rogamos a nuestros lectores que disculpen el error.

\section{CORRIGENDUM}

In the printed version of the article: Garbisu Buesa, Margarita: "La recepción de la música española en The Criterion a través de los escritos de John B. Trend". Anuario Musical 63: 153-180, (2008),

the following mistakes has been detected:

Pages 153, 155, 158, 162 and 180 [January 15th, 2010]: the British Hispanist "Edward M. Wilson" has been mistakenly cited as "Edgard M. Wilson"

Page 174 [March 29th, 2010]:

line 10: where it reads "M. Ernest Anserhe" it should read "Ernest Ansermet" línea 11: where it reads "en Granada" it should read "en Londres"

The mistakes has been corrected in this electronic version of the article on the dates quoted in square brackets.

A note will be also published in the next printed edition of the Journal.

We apologize to our readers for the inconvenience. 